\title{
California Agriculture delivers access to peer-reviewed research
}

In an era of publisher consolidation, when soaring journal prices increasingly limit the availability of science to those who can pay for it, the role of California Agriculture and other open-access journals is more important than ever - to deliver peer-reviewed science to the people who need it.

This year California Agriculture turns 60, making it one of the nation's oldest, continuously published land-grant university journals. With more than 14,000 domestic and international subscribers, and the full text posted on the Web since 2000, it is also one of the most widely disseminated journals of its kind.

California Agriculture and other land-grant publications have long been in the vanguard of those who delivered original, peer-reviewed research to subscribers without charge. (Although foreign subscribers pay a nominal fee, the journal is sent without charge to 1,200 foreign libraries.)

At one time, universities and nonprofit scientific societies published virtually the entire body of original, peer-reviewed research. In recent decades, the explosion of research has overwhelmed such traditional outlets and there are now tens of thousands of academic titles in circulation, many of them copyrighted by private corporations - with access granted to paying subscribers only.

The UC Office of Scholarly Communication notes that science, technology and medical publishers realize $20 \%$ to $30 \%$ annual profits in return for their massive publishing efforts (http: / / osc.universityofcalifornia.edu/). But a "merger effect" has also led to surging prices, creating a crisis in university libraries across the country.

Libraries have had to cancel journals and cut back book purchases, to keep up with the most essential online subscriptions and journals. Between 1986 and 2002, subscription costs increased 3.5 times the rate of inflation. Collectively, the UC libraries spent about \$64 million for scholarly materials in 2003; UC Berkeley pays over $\$ 900,000$ a year to just one publisher.

For individuals not affiliated with universities, the cost of downloading a single article can be as high as $\$ 35$, an expense compounded by the fact that vast sections of the literature are excluded for proprietary reasons from any one search. Such costs and restrictions are major obstacles to timely, comprehensive sharing of scientific information.

Universities and scientists have begun to counter this trend by taking control of their own research and publishing it in open-access journals or on unrestricted databases.

One such effort is UC's California Digital Library, whose eScholarship Repository supports the publication of journals and other scholarly materials from UC research units (http: / / www.cdlib.org/). Since its establishment in 2000, the Repository has logged over 2.2 million full-text downloads. California Agriculture's peer-reviewed articles will soon be posted at this site.
Another example is the open-access journal PLoS Biology, launched in October 2003 by the Public Library of Science. Evidence that scientists support such efforts came recently when the Institute for Scientific Information ranked PLoS Biology in the top tier of life science journals after just 2 years of operation. (The ranking is based on "journal impact factor," the average number of citations by other scientists per article.)

The commitment of faculty authors, associate editors and reviewers to research dissemination is also evident in every edition of California Agriculture. Just as it is critical to provide scientists comprehensive access to disciplinary research, it is equally important to deliver peer-reviewed science to the people who need it outside the research laboratory.

Although $31 \%$ of our audience consists of faculty and research scientists, the balance is a diverse mix of growers, private and public sector professionals, and elected officials and staff, all of whom can apply the research, whether in food and fiber production, environmental protection, human and community development, or public policy and mass media communications.

California Agriculture performs a broader educational function than faculty normally can achieve with technical publication in a disciplinary journal. It extends significant new findings to a wider readership, informing leaders and decision-makers who are not in the same disciplinary field of important developments. Among articles in this issue, for example, are several that examine our food decisions as a nation, from those made in Congress to those made by consumers in the grocery store.

As California's population has increased and diversified, California Agriculture's content has broadened to encompass the entire "culture" of agriculture - forestry, biodiversity, global warming, urban encroachment, hunger, diabetes and the obesity crisis, food safety, demographics, land use, biotechnology, and more.

The journal's authors and reviewers have also become more diverse. Today $18 \%$ of our authors are from outside ANR, whether from UC at large, other universities, public agencies or the private sector. In addition, $12 \%$ of reviewers are from outside the Division. Rigorous peer review results in $35 \%$ of articles being rejected or returned for resubmission.

The last stage of research is its dissemination, and the work of science is not complete until it has reached the hands of the people who can use it. California Agriculture is honored to be a part of the continuing tradition of delivering scientific research to the people whose tax dollars have already paid for its generation.

(Tell us why you read California Agriculture, and what you want to see in these pages in the future. We have posted a survey at http://californiaagriculture.ucop.edu. You may also e-mail us at calag@ucop.edu or write us at the address opposite. -Ed.) 